\title{
Ethical Considerations in Case Report Writing
}

Since the emergence of scientific communication, case reports have served in the advancement of our understanding of diverse scientific topics and have been the foundation to clinical care and research efforts. As clinicians, when dealing with a clinical case which presents a uniqueness related to its diagnostic process, treatment approach, evolution of the intervention, or even the final outcome; we are sometimes attracted to the idea of publishing it in the form of a case report. Such cases must be, in some way, novel and interesting, but more significantly, ethically sound. Therefore, which are the current ethical issues to consider when writing and publishing case reports?

Because of their intrinsic nature, case reports are usually found in the blurry area between regular healthcare and research, and for such reason, the commitment of the caregiver with the patient must always stand prior to any academic advance. This commitment should be initiated by a good reciprocal communication and mutual respect to guarantee the patient's consent to all the required procedures. Consequently, informed consent is the first of the ethical considerations the author of the case report must be aware of. A written authorization for any use or disclosure of protected health information is mandatory before publishing a case report. The patient or the patient's representative (in case of a minor) must clearly understand what information will be used, how it will be used and where will it be published, before the author submits the article. To encourage transparency in the decision making and treatment selection, the sooner the clinician can obtain this consent the better. There has been some debate on whether a case report should be considered as research, and if not, whether the clinician needs an informed consent or just a permission to publish the case report. If we scrutinize the modern, post-Nuremberg Code, concept of an informed consent, some of the elements of this legal document are not extended to the case report. In any case, a document enclosing the patient's agreement to publish all the necessary information must be obtained and, if possible, the patient should be allowed to read the case report final draft, before submission to approve or disapprove.

The second ethical consideration authors of case reports must consider when writing the manuscript is confidentiality. The safeguard of a patient's personal information and the materials (photographs, radiographs, dental models, and all other materials obtained from the patient) that will be used for the case report, must be carefully managed to avoid the involuntarily disclosure of the patient's privacy. The release of confidential information, in the form of a published case report article, without the permission of the patient could be perceived as a violation of the patient's autonomy since the individual had no opportunity to authorize disclosure or decline permission. Accordingly, in order to protect the patient's

MONTERO-AGUILAR M., 2021: Ethical Considerations in Case Report Writing.-ODOVTOS-Int. J. Dental Sc., 23-2 (May-August): 8-9. 
confidentiality, all personal identifiers must be removed from the case report's figures and special care must be taken in the data contained in description of the case so that the individual cannot be identified. Achieving this may present the author with an ethical challenge between maintaining confidentiality and providing key information to describe the case.

Finally, there still much discordance among scientific journals on the compulsion of the informed consent from the patient to publish a case report. Some journals request the approval of an institutional review board to revise that the information contained in the report is ethically appropriate and the confidentiality has been preserved. The ODOVTOS International Journal of Dental Sciences, as an official scientific publication of the University of Costa Rica and according to local legislation, endorses the requirement of an explicit statement, for the case report articles, where the authors mention that a written informed consent with the permission to publish was obtain previous of the article publication. Also, the authors must be able to provide this document if required. If an author is uncertain about the ethical aspects of a case report, it is better to consult with the journal's editor before submitting the article.

\section{Mauricio Montero-Aguilar MSc ${ }^{1}$}

1. Co-Editor-in-Chief. ODOVTOS-International Journal of Dental Sciences. http://orcid.org/0000-0002-3979-259X

Email: mauricio.monteroaguilar@ucr.ac.cr

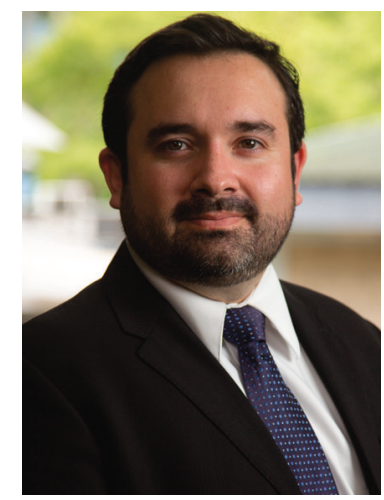

Attribution (BY-NC) - (BY) You must give appropriate credit, provide a link to the license, and indicate if changes were made. You may do so in any reasonable manner, but not in any way that suggest the licensor endorses you or your use. (NC) You may not use the material for commercial purposes. 